\begin{tabular}{|c|c|}
\hline \multirow{3}{*}{ 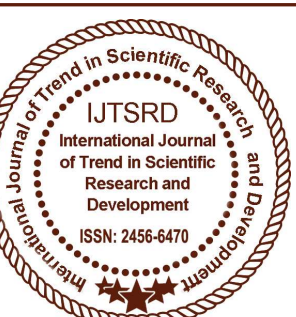 } & $\begin{array}{l}\text { International Journal of Trend in Scientific } \\
\text { Research and Development (IJTSRD) }\end{array}$ \\
\hline & International Open Access Journal \\
\hline & ISSN No: 2456 - 6470 | www.ijtsrd.com | Volume - 2 | Issue - 1 \\
\hline
\end{tabular}

\title{
Lipopolysaccharide promotes the metastatic Potential of Lung Carcinoma Cells by Upregulating the Expression of Fibronectin
}

\author{
Asif Amin \\ National Post-Doctoral Fellow \\ National Institute of Immunology \\ New Delhi, India \\ Asrar H. Wafai \\ Senior Research Fellow \\ Department of Biotechnology \\ University of Kashmir, Srinagar, J\&K, India
}

\author{
Taseem A. Mokhdomi \\ Senior Research Fellow \\ Department of Biotechnology \\ University of Kashmir, Srinagar, J\&K, India \\ Raies A. Qadri \\ Professor \& Head \\ Department of Biotechnology \\ University of Kashmir, Srinagar, J\&K, India
}

\section{ABSTRACT}

Lipopolysaccharide (LPS) stimulated TLR-4 mediated signalling has been shown to accentuate the metastasis in a variety of cancers. In a murine mammary cancer model, LPS has been found to trigger lung metastasis. However there are very few studies which report the pro-tumor properties of LPS in lung cancer. In this study we investigated the effect of LPS on Fibronectin induced metastatic progression in human lung cancer cells. Lower concentrations of LPS exhibited a pro-proliferative effect on A549 cells. Using such concentrations of LPS to stimulate A549 cells, expression of Fibronectin mRNA increased in comparison to control. $0.5 \mu \mathrm{g}$ of LPS treatment led to the two fold increase in mRNA expression of Fibronectin. Moreover, LPS stimulation augmented the migratory ability of A549 cells as assessed by wound healing assay. This increase in migration of A549 cells was in agreement with the expression pattern of Fibronectin induced by LPS stimulation. Taken together this study presents a preliminary account of the role of LPS in inducing the expression of Fibronectin and metastatic progression in lung carcinoma.

Keywords: Lipopolysaccharide; Fibronectin; Lung Carcinoma

\section{INTRODUCTION}

Lipopolysaccharide (LPS) also known as endotoxin constitutes the major molecular component of the outer membrane of Gram-negative bacteria. The host immune system recognizes LPS as a marker of bacterial invasion. Toll like receptors (TLRs) as an innate immune mechanism play a pivotal role in mediating the host inflammatory responses by recognizing signature molecules on microbial surfaces referred to as pathogen associated molecular patterns (PAMPs) such as LPS $(1,2)$. The complex formed between TLR4 and myeloid differentiation factor (MD2) represents a major cell surface receptor for lipopolysaccharide. LPS binds to the TLR4/MD2 receptor complex and initiates the intracellular signaling cascade leading to the activation of various downstream Mitogen-Activated Protein Kinases in a MyD88-dependant or MyD88-independent manner. Such signaling cascades have been shown to play key roles in cell proliferation, apoptosis, and adhesion (35).

The role of LPS is tumor progression and metastasis remains controversial with both anti and pro-tumor properties being reported. The anti-tumorigenic properties of LPS have been reported for the treatment of colorectal cancer and glioblastoma 
multiforme. An increasing body of evidence also points at the role of LPS in tumor progression. Stimulation of TLR4 by LPS has been found to trigger increased lung metastasis in a murine mammary cancer model of metastatic disease. This effect was ascribed to an increased proliferation and inhibition of apoptosis of tumor cells as well as an tumor cell invasion and migration along with increased angiogenesis $(6,7)$. Besides this study, TLR4 has been implicated in tumor cell invasion, survival, and metastasis in many cancer types (8). A recent study demonstrated that LPS can increase the migration ability of human cell esophageal cancer HKESC-2 cells via signaling through TLR4 (9). Similarly in breast cancer TLR4 activation by LPs has been shown to promote the $\alpha v \beta 3$-mediated adhesion and invasiveness (10).

\section{Materials and Methods}

\section{A. Chemicals and reagents}

DMEM and FBS were procured from Gibco, USA. Penstrip was obtained from Invitrogen, USA. LPS (Escherichia coli 0111:B4), DMSO and MTT were purchased from Sigma Chemical Co. (St. Louis, MO, USA). LPS was prepared as a stock solution of 1 $\mathrm{mg} / \mathrm{ml}$ and was diluted to various concentrations with serum free medium when used.

\section{B. Cell culture}

Human lung carcinoma cell line, A549 was provided by Dr. Ayub Qadri, National Institute of Immunology. A549 Cells were cultured in DMEM, supplemented with $10 \%$ fetal bovine serum, and antibiotics (1\% penstrip) at $37{ }^{\circ} \mathrm{C}$ in $5 \% \mathrm{CO} 2$ humidified incubator. The medium was changed regularly and the cells were sub-cultured when confluent.

\section{MTT Cell Proliferation Assay}

Cells were seeded into the wells of a 96 well plate and allowed to grow overnight. LPS was added to cells at various concentrations $(0.1,0.5,1,1.5,2$ and $2.5 \mu \mathrm{g})$ for $24 \mathrm{~h}$. Following treatment, $100 \mu \mathrm{l}$ of MTT solution was added to each well followed by $2 \mathrm{~h}$ incubation at $37^{\circ} \mathrm{C}$ in dark. Then the MTT solution was removed and $100 \mu 1$ of DMSO was added to cells. The quantification was done by measuring the absorbance at $590 \mathrm{~nm}$ (background $650 \mathrm{~nm}$ ) using micro plate reader (Biotek, USA) and the percentage proliferation was calculated.

\section{Reverse transcriptase polymerase chain reaction}

RNA was isolated using TRIzol reagent according to manufacturer's instructions. Briefly $1 \mathrm{ml}$ of TRIzol was added to the cells grown in $30 \mathrm{~mm}$ culture dish followed by homogenization using a pipette. Thereafter $1 \mathrm{ml}$ of sterile water was added and the mixture incubated at room temperature for 5-15 $\mathrm{min}$. The mixture was centrifuged at $12,000 \mathrm{~g}$ for $15 \mathrm{~min}$ and supernatant collected, to which $70 \%$ isopropanol was added. The supernatant was further centrifuged at $12,000 \mathrm{~g}$ for $10 \mathrm{~min}$ to obtain the RNA pellet which was washed two times with $75 \%$ ethanol. The integrity of RNA was checked on 1\% agarose gel. In succession to RNA isolation and subsequent quantification, RNA was reverse transcribed to cDNA using reverse transcriptase and oligo-dT primers in a final volume of $20 \mu \mathrm{l}$.

The primers used for evaluating the expression status of Fibronectin are as:

Forward

5...AGTCAGCCTCTGGTTCAGAC...3

primer

Reverse

primer

5...CTTCAGGTCAGTTGGTGCAG...3

PCR products were analyzed on 1-2\% agarose gels and the ratio of TLR4 to $\beta$-actin served as the level of mRNA expression.

\section{E. Real Time PCR}

Real-time PCR was performed to detect the gene expression of Fibronectin in A549 cells under LPS stimulation. The $10 \mu \mathrm{l}$ reaction mixture contained 5.5 $\mu \mathrm{l}$ nuclease-free water, $1.0 \mathrm{ml}$ cDNA $(1 \mathrm{mg} / \mathrm{ml}), 0.5$ $\mu \mathrm{l}(10 \mathrm{mM})$ each primer and $2.5 \mu \mathrm{l}$ Light Cycler 480 SYBR Green Master (Roche, Germany). The amplification was carried at $94{ }^{\circ} \mathrm{C}$ for $2 \mathrm{~min}$ incubation and 40 cycles of $94{ }^{\circ} \mathrm{C}$ for $15 \mathrm{~s}, 56^{\circ} \mathrm{C}$ for $15 \mathrm{~s}, 72^{\circ} \mathrm{C}$ for $20 \mathrm{~s}$, followed by final extension of 72 ${ }^{\circ} \mathrm{C}$ for $2 \mathrm{~min}$ in LightCycler 480 II (Roche, Germany). Relative quantification was done using 2 ${ }^{\Delta \Delta \mathrm{cp}}$ method (11).

\section{F. Cell migration Assay}

Equal number of A549 cells was seeded in each well of 24-well plate and allowed to grow to subconfluency. Then the scratch was created using a 100 $\mu l$ pipette tip followed by washings with PBS to 
remove the floating cells. This was followed by treatment with sub-toxic concentrations of LPS for 24 h. Photographs were taken before $(0 \mathrm{~h})$ and after treatment at $24 \mathrm{~h}$. Wound healing was calculated as the percentage of the initial wound before treatment to the total wound closure at $24 \mathrm{~h}$ after treatment. The assay was performed three independent times.

\section{RESULTS}

\section{A. Determination of Sub-lethal doses of LPS}

Exposure to bacterial LPS has been shown to induce apoptotic cell death. In order to determine the Sublethal doses of LPS, A549 cells were treated with different concentrations of LPS. It was observed that LPS did not result in appreciable inhibition of cell proliferation up to $1 \mu \mathrm{g}$ of LPS. However the doses exceeding $1 \mu \mathrm{g}$ had a significant impact on the proliferation of A549 cells. Therefore we only used sub-lethal concentrations of LPS for further assays (Figure 1).

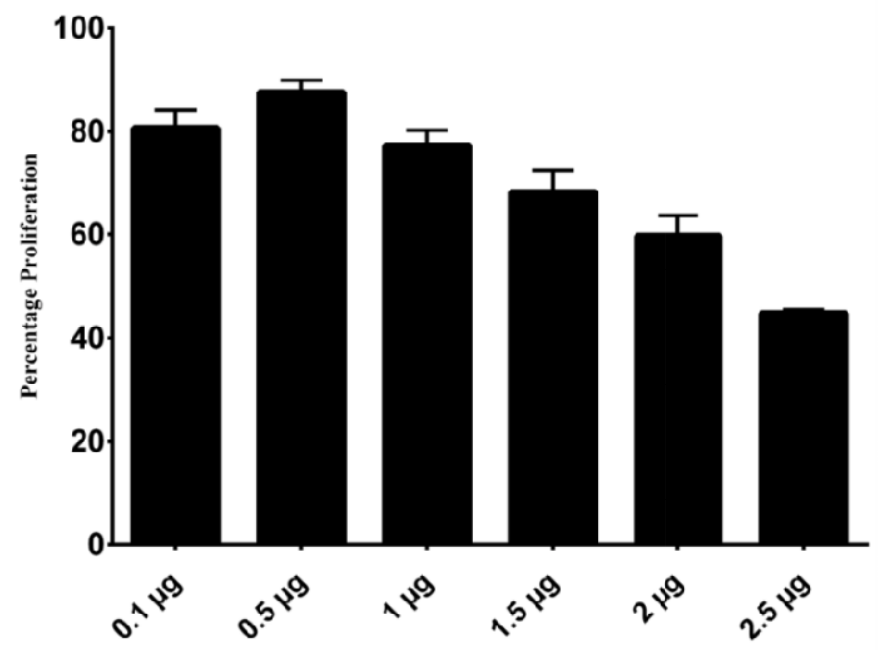

Figure 1. Evaluation of sub-lethal doses of LPS on A549 cells by MTT assay. A549 cells were treated with the indicated concentrations of LPS for $24 \mathrm{~h}$. After $24 \mathrm{~h}$, cytotoxicity was determined by MTT assay. Data represented as mean $\pm \mathrm{SD}$ of results from three independent experiments.

\section{B. Treatment with LPS increases the expression of Fibronectin in A549 cells}

Fibronectin has been shown to promote metastatic behavior of many tumors including those of lung. Therefore to assess the effect of LPS on the expression of Fibronectin, A549 cells were exposed to various sub-lethal concentrations $(0.1,0.5$ and 1 $\mu \mathrm{g})$ of LPS for $24 \mathrm{~h}$. Following treatment, RNA was isolated from A549 cells using trizol reagent (Figure 2).

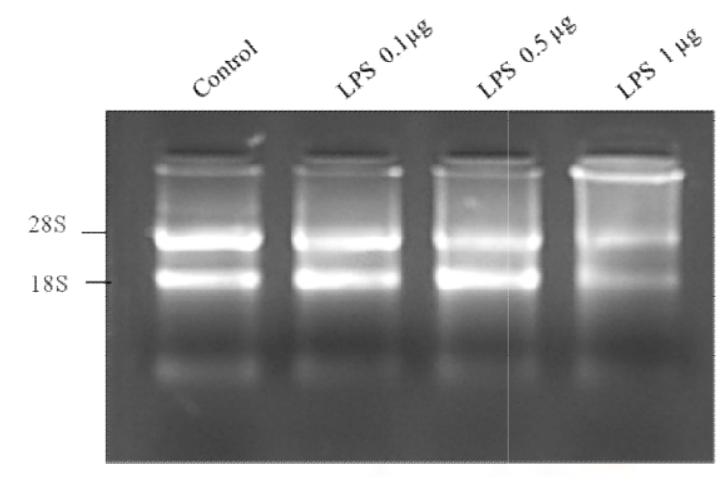

Figure 2. RNA isolation from control and LPS treated cells

The extracted RNA was reverse transcribed to cDNA using oligo dT primers. To evaluate the effect of LPS treatment on the expression of Fibronectin at mRNA level, cDNA obtained was amplified using specific primers. It was observed that the treatment with LPS led to the increase in the expression of Fibronectin particularly at $0.6 \mu \mathrm{g}$ concentration (Figure $3 \mathrm{~A}$ ). However at $0.1 \mu \mathrm{g}$ there was decrease in the gene expression of Fibronectin as compared to untreated control. For further quantitative analysis, real-time PCR was carried out and the results obtained were in consonance with those obtained by semi-quantitative analysis (Figure 3B). Real-Time PCR analysis revealed that the Fibronectin gene expression gets upregulated 2 fold using $0.6 \mu \mathrm{g}$ LPS in comparision to untreated control.

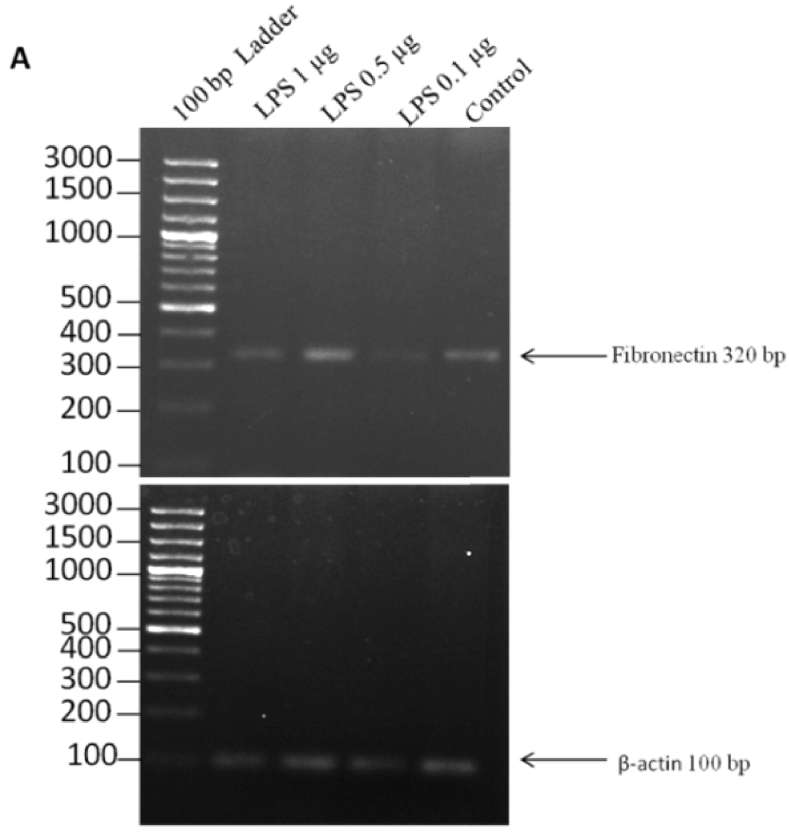


B

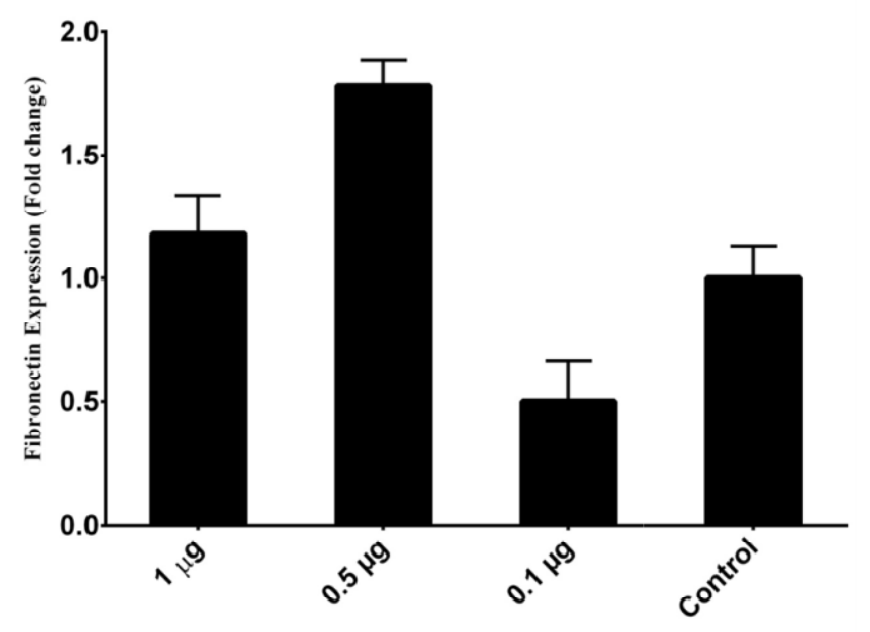

Figure 3. Gene expression analysis of Fibronectin in LPS stimulated A549 cells by (A) Semi quantitative reverse transcription PCR (B) Real Time PCR. Data represented as mean $\pm \mathrm{SD}$ of results from three independent experiments.
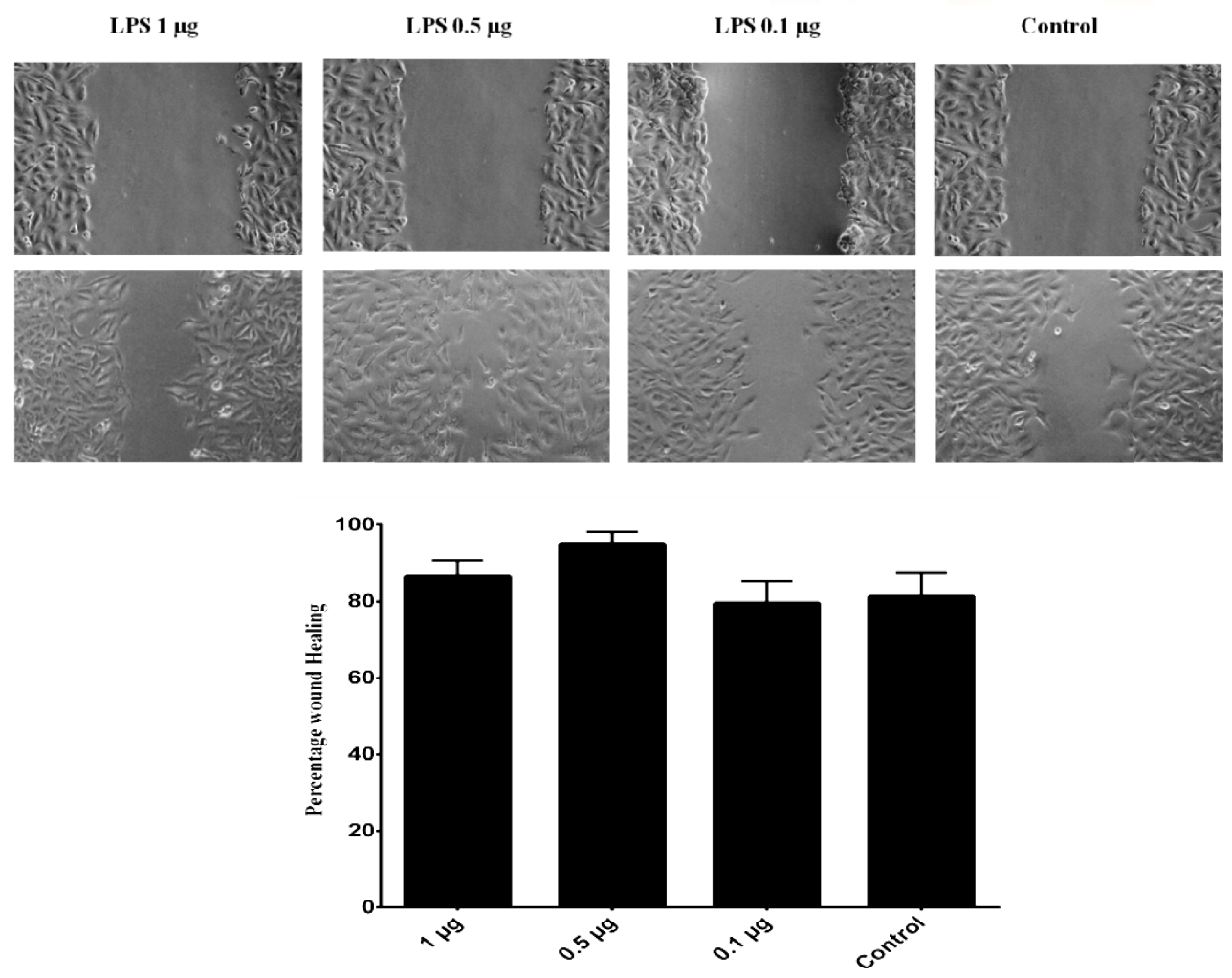

Figure 4. Effect of LPS on the migration of A549 cells. A549 cells were grown to sub-confluency, wounded and treated with indicated concentrations of LPS or left untreated (control). (A) Wound healing observed after 24h. (B) The data calculated from three independent experiments and represented as mean \pm SD.

\section{DISCUSSION}

Fibronectin is an extracellular matrix glycoprotein that has been shown to promote metastatic process in a wide variety of cancer types. It has been implicated in

\section{Treatment with LPS accentuates the migration of A549 cells}

Migration and invasion represent the processes crucial to metastasis. Fibronectin has been shown to enhance the migration and invasiveness of lung carcinoma cells. To evaluate the effect of LPS on the migration of A549 cells, a wound healing assay was carried out. A549 cells were grown to confluency, wounded and then treated with indicated concentration of LPS. It was observed that LPS stimulation led to the healing of wound with best concentration being $0.5 \mu \mathrm{g}$. In terms of percentage wound healing, while treatment with $1 \mu \mathrm{g}$ and $0.5 \mu \mathrm{g}$ led to the healing of wound to about $86 \%$ and $95 \%$ respectively while as $0.1 \mu \mathrm{g}$ was not much effective when compared with the control (Figure 4). 
profound consequences on tumor growth as they have been found to promote cancer progression and antiapoptotic activity (6-8). In a recent study NADPH oxidase 1-dependent ROS was demonstrated to be crucial for TLR4 signaling to promote tumor metastasis of non-small cell lung cancer (14). In this way, we therefore designed this study to determine the action of LPS on Fibronectin induced metastatic progression in lung carcinoma cells. A549 cells were stimulated with sub-lethal doses of LPS. At such concentrations there was an increase in the proliferation of these cells. Furthermore treatment with such concentrations led to increase in the expression of Fibronectin at mRNA level as was assessed by semi-quantitative reverse transcription PCR as well as quantitative real time PCR. To further assess the effect of LPS on the migration, A549 cells were treated with sub-lethal concentrations of LPS. It was observed that the treatment with LPS increased the migratory ability of A549 cells as was depicted by significant closure of the wound. The finding was in coherence with the upregulation of Fibronectin by LPS treatment. Thus it can be argued that LPS accentuates the metastatic process in lung cancer cells by upregulating the expression of Fibronectin. The present study presents a preliminary account of effect of LPS on Fibronectin induced metastatic progression in lung carcinoma and thus warrants an exhaustive study to discern the mechanistic action of LPS.

\section{References}

1) [1] Janeway CA Jr, Medzhitov R. (2002) Innate immune recognition. Annual Reviews of Immunolgy. 20: 197-216.

2) [2] Akira S, Uematsu S, Takeuchi O. (2006) Pathogen recognition and innate immunity. Cell 124: 783-801.

3) [3] Kim HM, Park BS, Kim JI, Kim SE, Lee J, Oh SC, et al (2007) Crystal structure of the TLR4-MD2 complex with bound endotoxin antagonist Eritoran. Cell 130: 906-17.

4) [4] Park BS, Song DH, Kim HM, Choi BS, Lee H, Lee JO. (2009) The structural basis of lipopolysaccharide recognition by the TLR4-MD-2 complex. Nature 458: 1191-5.

5) [5] Lu YC, Yeh WC, Ohashi PS. (2008). LPS/TLR4 signal transduction pathway. Cytokine 42: $145-51$.

6) [6] Pidgeon GP, Harmey JH, Kay E, Da Costa M, Redmond HP, Bouchier-Hayes DJ. (1999) The role of endotoxin/lipopolysaccharide in surgically induced tumour growth in a murine model of metastatic disease. British Journal of Cancer. 81: $1311-7$.

7) [7] Harmey JH, Bucana CD, Lu W, Byrne AM, McDonnell S, Lynch C, et al. (2002) Lipopolysaccharide-induced metastatic growth is associated with increased angiogenesis, vascular permeability and tumor cell invasion. International Journal of Cancer.101: 415-22.

8) [8] Yang H, Wang B, Wang T, Xu L, He C, Wen $\mathrm{H}$, et al. (2014) Toll-like receptor 4 prompts human breast cancer cells invasiveness via lipopolysaccharide stimulation and is overexpressed in patients with lymph node metastasis. PLoS ONE .9: $\mathrm{e} 109980$

9) [9] Rousseau MC, Hsu RY, Spicer JD, Mcdonald B, Chan CH, Perera RM, et al. (2013) Lipopolysaccharide-induced toll-like receptor 4 signaling enhances the migratory ability of human esophageal cancer cells in a selectindependent manner. Surgery.154: 69-77.

10) [10] Liao SJ, Zhou YH, Yuan Y, Li D, Wu FH, et al. (2012) Triggering of Toll-like receptor 4 on metastatic breast cancer cells promotes avb3mediated adhesion and invasive migration. Breast Cancer Research and Treatment. 133: 853-63.

11) [11] Livak KJ, Schmittgen TD (2001) Analysis of relative gene expression data using real- time quantitative PCR and the 2- $\Delta \Delta \mathrm{cp}$ Method. Methods. 25: 402-408

12) [12] Ou, J., Peng, Y., Deng, J., Miao, H., Zhou, J., Zha, L., Liang, H. (2014). Endothelial cell-derived fibronectin extra domain A promotes colorectal cancer metastasis via inducing epithelialmesenchymal transition. Carcinogenesis. 35: 16611670

13) [13] Amin, A., Chikan, N. A., Mokhdomi, T. A., Bukhari, S., Koul, A. M., Shah, B. A., \& Qadri, R. A. (2016). Irigenin, a novel lead from Western Himalayan chemiome inhibits Fibronectin-Extra Domain A induced metastasis in Lung cancer cells. Scientific Reports. 6.

14) [14] Liu X, Pei C, Yan S, Liu G, Liu G, Chen W et al. (2015) NADPH oxidase 1-dependent ROS is crucial for TLR4 signaling to promote tumor metastasis of non-small cell lung cancer. Tumor Biology. 6: 1493-1502. 